\title{
Neural unit activity in an anterior "nonspecific" cortical area during classical conditioning of the rabbit's nictitating membrane response
}

\author{
FRED K. HOEHLER and RICHARD F. THOMPSON \\ Department of Psychobiology, University of California, Irvine, California 92717
}

\begin{abstract}
Neural unit activity was recorded from a region in motor-sensory cortex that had previously been shown to produce systematic increases in unit activity during avoidance learning. Although there were small unlearned responses evoked by both CS (tone) and US (air puff), there was no apparent neural plasticity associated with classical conditioning of the nictitating membrane response.
\end{abstract}

The role of the neocortex in classical conditioning has always been controversial. Pavlov (1927) felt that the cerebral cortex was necessary for conditioning, but more recent data have tended to dispute that position. For example, classical conditioning of the rabbit's nictitating membrane (NM) response appears to be relatively unaffected by neocortical destruction (Oakley \& Russell, 1972, 1976). However, it seems likely that the cortex may participate in conditioning in intact animals, since functional lesions produced by the application of $\mathrm{KCl}$ to the dura (spreading depression) eliminate previously acquired conditioned responses (Gutman, Brozek, \& Bureš, 1972; Megirian \& Bureš, 1970; Papsdorf, Longman, \& Gormezano, 1965).

In this laboratory, we have been investigating neural unit activity in various central nervous system structures during classical conditioning (tone CS; corneal air puff US) of the rabbit's NM response. As might be expected, units in motor structures involved in control of the NM response, such as the abducens nucleus, show a pattern of responding very closely correlated with the topography of the behavioral response (Cegavske, Patterson, \& Thompson, 1979), whereas units in sensory (e.g., auditory) structures display short-latency evoked responses to $\mathrm{CS}$ and US onset that are apparently unrelated to learning (Lonsbury-Martin, Martin, Schwartz, \& Thompson, 1976; Thompson, Berger, Cegavske, Patterson, Roemer, Teyler, \& Young, 1976). Units in limbic system structures such as hippocampus

This study was supported by research grants from NIMH (MH26530), NIH (NS 23368), NSF (BMS 75-00453), the McKnight Foundation, and NIMH Postdoctoral Fellowship MH 05041 to F. K. Hoehler. This work was brought to completion while the second author was a fellow of the Center for Advanced Study in the Behavioral Sciences, Stanford, California, with the support of Center funds and funds from NIMH (5T 32 MH 14581-03) and NSF (BNS 76-22943 A02). We thank Carol Cooper for histology and Michael Ross for assistance. Fred K. Hoehler's current address is Department of Physical Medicine and Rehabilitation, California College of Medicine, University of California, Irvine, California 92664.
(Berger \& Thompson, 1978a; Hoehler \& Thompson, in press), lateral septum (Berger \& Thompson, 1978b), and entorhinal cortex (Clark, Berger, \& Thompson, 1978) show more complex effects but generally tend to produce increases in multiple-unit activity that are highly correlated with the development of the behavioral conditioned response.

There is some evidence for learning-dependent plasticity in certain areas of neocortex (see, e.g., Shul'gina, 1970; Shvyrkov, in press; Sokolov, 1977; Thompson, Patterson, \& Teyler, 1972). Gabriel, Wheeler, and Thompson (1973a, 1973b) examined multiple-unit activity in three "nonspecific polysensory" areas of rabbit neocortex and found increased activity in two of them during instrumental avoidance learning. In the present experiment, we examined multiple-unit activity in one of those areas during classical conditioning of the rabbit's NM response. The area investigated has been termed "anterior nonspecific" (AN) and has been defined as a polysensory association area on the basis of evoked potential mapping (Gabriel et al., 1973b). It lies in medial motor-sensory cortex overlapping the hindlimb representation. Although this anterior region did not produce reliable generalization gradients (Gabriel et al., 1973a), it did produce conditioned increases in multipleunit activity that were time-locked to the CS, occurring within $50 \mathrm{msec}$ of CS onset. In the limbic system, neuronal plasticity during classical conditioning becomes closely time-locked to the learned behavioral response, with maximal unit activity occurring immediately prior to US onset (e.g., Berger \& Thompson, 1978a; Hoehler \& Thompson, in press), and it seemed possible that plasticity in the immediate neuronal response to the CS might occur in the nonspecific polysensory areas of the neocortex.

\section{METHOD}

Methods for the implantation of cortical electrodes were the same as those reported by Gabriel et al. (1973a, 1973b). Briefly, albino New Zealand rabbits were anesthetized and "multiple- 
unit" stainless steel microelectrodes (5-micron tip diameter, 50-micron shaft exposure) were chronically implanted in the anterior motor-sensory area of the right hemisphere $1 \mathrm{~mm}$ lateral to the midline at bregma. Electrodes were advanced at least $1 \mathrm{~mm}$ below the dura, and greater penetrations were often made in order to obtain large-amplitude multiple-unit spikes. For purposes of comparison, some animals also had electrodes implanted in the dorsal hippocampus. Methods for this procedure as well as methods of behavioral training and data analysis were identical to those reported previously (Berger \& Thompson, 1978a, 1978b; Hoehler \& Thompson, in press). Briefly, microelectrodes were localized in the CA1 layer of the left dorsal hippocampus both with stereotaxic coordinates $(4.5 \mathrm{~mm}$ caudal and $5.5 \mathrm{~mm}$ lateral to bregma) and with physiological recording during implantation. Seven to 10 days after the completion of surgery, subjects received one session of adaptation to the apparatus followed by two daily sessions of classical conditioning of the NM response using a tone $(1,000 \mathrm{~Hz}, 85 \mathrm{~dB}, 350 \mathrm{msec})$ as the CS and an air puff $\left(210 \mathrm{~g} / \mathrm{cm}^{2}, 100 \mathrm{msec}\right)$ delivered to the left eye as the US. In the paired group $(n=5)$, CS onset preceded US onset by $250 \mathrm{msec}$ except on test trials, in which the CS was presented alone. Subjects in the unpaired group $(n=4)$ received a quasirandom schedule of CSs and USs, which were never contiguous in time. After behavioral training, subjects were anesthetized and perfused with $.9 \%$ saline followed by $10 \%$ formalin. The brains were removed, frozen, sectioned, and photographed while still wet and stained with cresyl violet (cortex) and Prussian blue (hippocampus). Data were used only if the tip of the cortex electrode could be localized in Layers II, III, IV, or V of the cerebral cortex. Hippocampal recordings were used only if the electrode tip could be localized in or near the pyramidal cell layer of the dorsal hippocampus.

\section{RESULTS AND DISCUSSION}

There was no evidence of cortical neuronal plasticity correlated with the acquisition of the behavioral response. Figure 1 shows NM response topographies and cortical unit poststimulus histograms averaged over all subjects. In the paired conditioning animals (Figure 1, left panel),

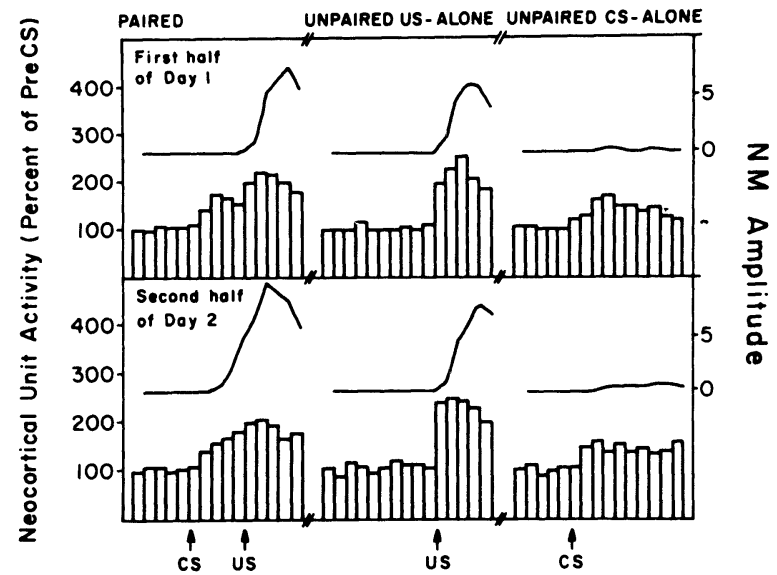

Figure 1. Averaged NM response topographies and cortical (anterior nonspecific) multiple-unit poststimulus histograms averaged over the first half of Day 1 (upper panels) and the second half of Day 2 (lower panels). All traces are based on the average of 48 trials and are grouped in bins of $48 \mathrm{msec}$. Arrows indicate CS and US onsets. Left traces = paired subjects; center traces $=$ unpaired subjects, US-alone trials; right traces $=$ unpaired subjects, CS-alone trials.

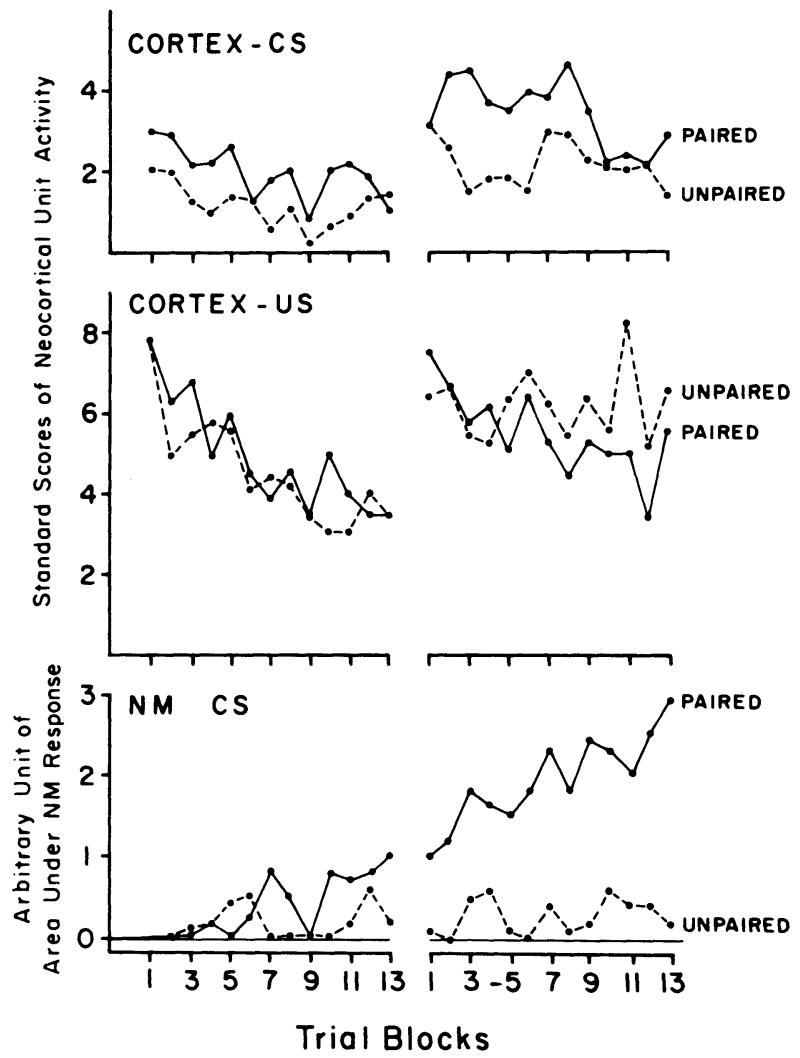

Figure 2. Group curves of standard scores of cortical multiple-unit activity during the CS period (upper panel) and the US period (middle panel). Also shown are integrated areas under the curve of the NM response during the CS period (lower panel). Solid lines $=$ paired conditioning group $(N=5)$; broken lines = unpaired control group $(\mathrm{N}=4)$.

a diffuse evoked increase in unit activity was present from the beginning of training (first half of Day 1, above), but it clearly was not correlated with the learned behavioral response, which did not appear until Day 2 . Furthermore, there were also evoked increases in unit activity to air puff and to tone in the unpaired controls (Figure 1, center and right panels). This evoked unit activity, incidentally, resembled evoked activity recorded from the polysensory cortical association areas of the unanesthetized cat, in that it had a longer onset latency than primary cortical evoked responses and was polysensory (see Gabriel et al., 1973a; Robertson, Mayers, Teyler, Bettinger, Birch, Davis, Phillips, \& Thompson, 1975; Thompson \& Shaw, 1965).

Figure 2 presents standard scores (see Berger \& Thompson, 1978a, 1978b) of cortical unit activity (averaged over eight-trial blocks) during the CS and the US periods, as well as areas under the curve of the conditioned NM response. Analyses of variance revealed that the only statistically significant neuronal effect over trials was the decline (habituation?) in multiple-unit activity over blocks of trials on Day 1 [CS period: $F(12,84)=2.67, p<.01 ;$ US period: $F(12,84)=6.07$, 


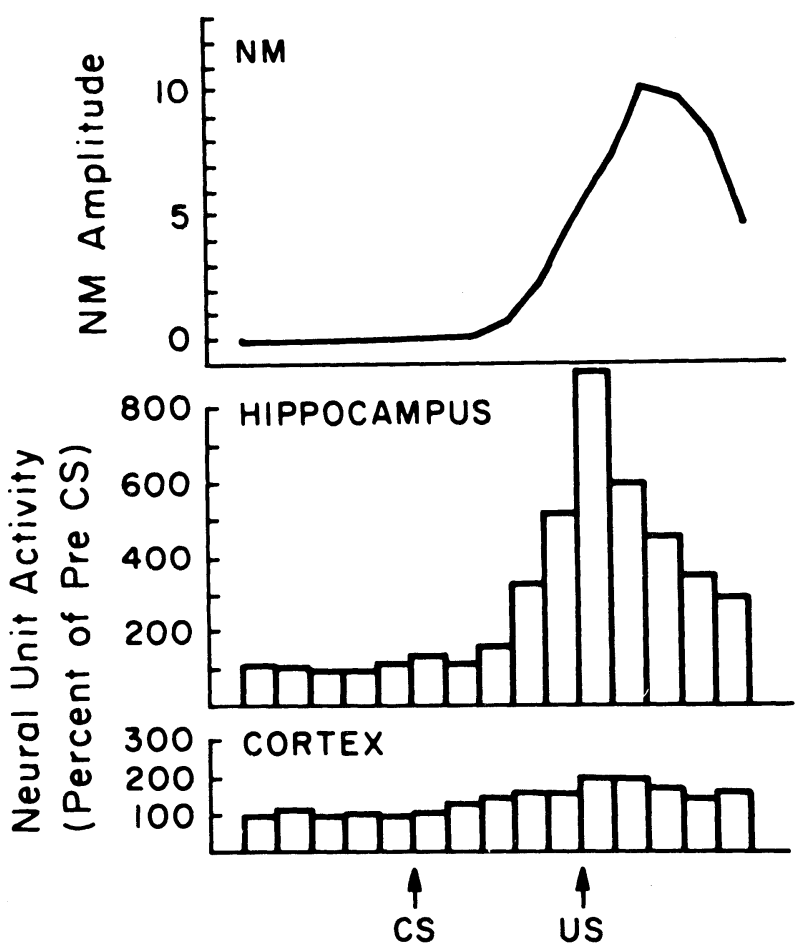

Figure 3. Averaged NM response topography (upper panel) and poststimulus histograms of hippocampal (middle panel) and cortical (lower panel) unit activity in four of the paired conditioning animals. Arrows indicate CS and US onsets. Note that the $y$-axis for poststimulus histograms is more compressed than in Figure 1.

$\mathrm{p}<.01]$. In contrast, the averaged areas under the curve of the NM response during the CS period showed a clear difference between paired and unpaired groups on Day $2[F(1,7)=9.96, p<.05]$. The evoked cortical unit activity to the US, incidentally, was substantially higher than that to the CS at the beginning of training (see Figures 1 and 2).

Figure 3 presents simultaneously recorded cortical unit data from four paired subjects (second half of Day 2) who also had electrodes implanted in the dorsal hippocampus. In agreement with previous reports, the hippocampus exhibited large conditioned increases in multiple-unit activity that closely modeled the amplitude-time course of the conditioned NM response (Berger \& Thompson, 1978a, 1978b; Hoehler \& Thompson, in press; Thompson et al., 1976), while the anterior nonspecific cortex did not.

The absence of acquisition-related effects in this particular cortical area does not, of course, imply that other areas of neocortex are not involved in classical NM conditioning. However, this area has been shown to produce systematic increases in multiple-unit activity during avoidance conditioning (Gabriel et al., 1973b). There are at least two possible explanations for this difference. One concerns the paradigms: Perhaps this anterior "nonspecific" motor-sensory region plays a role in instrumental but not in Pavlovian conditioning. The other concerns motor-sensory cortical representation: This area is in the region of hindlimb representation (Woolsey, 1958). In the instrumental avoidance paradigm used by Gabriel et al. (1973b), the animal learns to move its hindlimbs. This possibility can be tested for the rabbit NM system by recording from the cortical motor-sensory region of eye representation, which lies more lateral. The finding of Gutmann et al. (1972) that spreading depression of the eye representation field in motor-sensory cortex of the rabbit reversibly blocks the conditioned eyelid response suggests that conditioned increases in unit activity might occur in this region during classical conditioning of the NM response.

\section{REFERENCES}

Berger, T. W., \& Thompson, R. F. Neuronal plasticity in the limbic system during classical conditioning of the rabbit nictitating membrane response. I. The hippocampus. Brain Research, 1978, 145, 323-346. (a)

Berger, T. W., \& Thompson, R. F. Neuronal plasticity in the limbic system during classical conditioning of the rabbit nictitating membrane. II: Septum and mammillary bodies. Brain Research, 1978, 156, 293-314. (b)

Cegavske, C. F., Patterson, M. M., \& Thompson, R. F. Neuronal unit activity in the abducens nucleus during classical conditioning of the nictitating membrane response in the rabbit, Oryctolagus cuniculus. Journal of Comparative and Physiological Psychology, 1979, 93, 595-609.

Clark, G. A., Berger, T. W., \& Thompson, R. F. The role of entorhinal cortex during conditioning: Evidence for entorhinal-dentate facilitation. Neuroscience Abstracts, 1978, 4, 667.

Gabriel, M., Wheeler, W., \& Thompson, R. F. Multiple unit activity of the rabbit cerebral cortex during stimulus generalization of avoidance behavior. Physiological Psychology, 1973, 1, 313-320. (a)

Gabriel, M., Wheeler, W., \& Thompson, R. F. Multiple-unit activity of the rabbit cerebral cortex in single session avoidance conditioning. Physiological Psychology, 1973, 1, 45-55. (b)

Gutmann, W., Broze K, G., \& Bureš, J. Cortical representation of conditioned eye blink in the rabbit studied by a functional ablation technique. Brain Research, 1972, 40, 203-214.

Hoenler, F. D., \& Thompson, R. F. Effect of the interstimulus (CS-UCS) interval on hippocampal unit activity during classical conditioning of the nictitating membrane response of the rabbit, Oryctolagus cuniculus. Journal of Comparative and Physiological Psychology, in press.

Lonsbury-Martin, B. L., Martin, G. K., Schwartz, S. M., \& Thом PSON, R. F. Neural correlates of auditory plasticity during classical conditioning in the rabbit. Journal of Acoustical Society of America, 1976, 60, S82.

Megirian, D., \& Bures, J. Unilateral spreading depression and conditioned eyeblink responses in the rabbit. Experimental Neurology, 1970, 27, 34-45.

OAKLEy, D. A., \& Russell, I. S. Neocortical lesions and Pavlovian conditioning. Physiology \& Behavior, 1972, 8, 915-926.

OAKLeY, D. A., \& Russell, I. S. Subcortical nature of Pavlovian differentiation in the rabbit. Physiology \& Behavior, 1976, 17, 947-954.

Papsdorf, J. D., Longman, D., \& Gormezano, I. Spreading depression: Effects of applying potassium chloride to the dura 
of the rabbit on the conditioned nictitating membrane response. Psychonomic Science, 1965, 2, 125-126.

Pavlov, I. Conditioned reflexes. New York: Oxford University Press, 1927.

Robertson, R. T., Mayers, K. S., Teyler, T. J., Bettinger, L., Birch, H., Davis, J. L., Phillips, D. S., \& Thompson, R. F. Unit activity in posterior association cortex of cat. Journal of Neurophysiology, 1975, 38, 780-794.

SHUL'GINA, F. I. Investigations of activity of cortical neurons in early stages of conditioning. In V. S. Rusinov (Ed.), Electrophysiology of the central nervous system. New York: Plenum Press, 1970.

Shvyrkov, V. B. Goal as a neuronal system-creating factor in behavior and learning. In R. F. Thompson, L. H. Hicks, \& V. B. Shvyrkov (Eds.), Neural mechanisms of goal-directed behavior and learning. New York: Academic Press, in press.

Sokolov, E. N. Brain functions: Neuronal mechanisms of learning and memory. Annual Review of Psychology, 1977, 28, 85-112.
Thompson, R. F., Berger, T. W., Cegavske, C. F., Patterson, M. M., Roemer, R. A., Teyler, T. J., \& Young, R. A. The search for the engram. American Psychologist, 1976, 31, 209-227.

Thompson, R. F., Patterson, M. M., \& Teyler, T. J. Neurophysiology of learning. Annual Review of Psychology, 1972, 23, 73-104.

Thompson, R. F., \& Shaw, J. A. Behavioral correlates of evoked activity recorded from association areas of the cerebral cortex. Journal of Comparative and Physiological Psychology, 1965, 60, 329-339.

WoOLSEY, C. N. Organization of somatic sensory and motor areas of the cerebral cortex. In C. M. Woolsey \& H. F. Harlow (Eds.), Biological and biochemical bases of behavior. Madison: University of Wisconsin Press, 1958.

(Received for publication December 5, 1979.) 